\title{
El Infinito En La Palma De La Mano (2013): Um Novo Génesis Desde A Perspectiva Latino-Americana De Gioconda Belli
}

\author{
El infinito en la palma de la mano (2013): un nuevo Génesis desde la \\ perspectiva latinoamericana de Gioconda Belli
}

\author{
María Pía Marcaida* \\ *Universidad Nacional de Tucumán, UNT, San Miguel de Tucumán, 491, 4000, e-mail: \\ mpmarcaida@ hotmail.com ${ }^{1}$ \\ Gilmei Francisco Fleck** \\ ** Universidade Estadual do Oeste do Paraná, UNIOESTE, Cascavel-PR, 85819-110, \\ e-mail: chicofleck@gmail.com ${ }^{2}$
}

\begin{abstract}
RESUMO: A ideia da escrita desse texto surgiu como resposta a algumas inquietudes suscitadas ao longo dos estudos sobre Literatura Comparada na América Latina ${ }^{3}$ e as posições defendidas por teóricos como Coutinho (19952004), Santiago (2000), Bernd (1998), entre outros. Entre elas está a necessidade imperiosa de tomar consciência das especificidades das diversas literaturas, assim como a de se estabelecer um diálogo em pé de igualdade entre as mesmas. Isso equivale a abordar especificamente a literatura dos distintos países latinoamericanos como uma dialética entre o local e o universal porque é nessa pluralidade onde ela pode e deve ser entendida, já que as literaturas latinoamericanas sempre receberam uma grande influência das europeias e assimilaram destas, como de outras, aspectos e características que, sem dúvida, no presente,
\end{abstract}

\footnotetext{
1 María Pía Marcaida - Profesora en Letras por la UNT/Argentina. Doctoranda en Letras por la UNT/Argentina. Integrante del grupo de investigación "Prácticas del discurso en espacios de mediación: traducción, literatura y enseñanza".

${ }^{2}$ Gilmei Francisco Fleck - Profesor Adjunto de la UNIOESTE/Cascavel en el Grado en Letras, en las áreas de Literatura y Cultura Hispánicas, y en el Pos-grado en Letras, en las áreas de Literatura Comparada y Traducción. Doctor en Letras por la UNESP/Assis. Vice-líder del grupo de investigación "Confluências da Ficção, História e Memória na Literatura e nas Diversas Linguagens". Coordinador del PELCA: Programa de Enseñanza de Literatura y Cultura. Becario de CAPES, en estancia pos-doctoral (2014-2015), en la UVIGO - Universidad de Vigo/España, desarrollando el proyecto "Romance histórico: produção, leitura e tradução - caminhos para a descolonização da América Latina". E-mail: chicofleck@yahoo.com.br

${ }^{3}$ El presente trabajo está enmarcado dentro de la producción colaborativa propuesta a partir del curso "Actualización teórica y práctica en el campo de la Literatura Comparada en el ámbito latinoamericano", ofrecido por la Secretaría de Posgrado de la Facultad de Filosofía y Letras de la Universidad Nacional de Tucumán-UNT, en noviembre de 2013. Dicho curso fue dictado por el profesor invitado de la UNT Doctor Gilmei Francisco Fleck, profesor adjunto de la "Universidade Estadual do Oeste do ParanáCascavel-PR/Brasil.
}

Volume 18

Número 40 


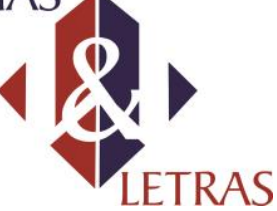

são substancialmente modificadas no momento da apropriação. Por isso este artigo analisará a reconstrução da história de Adão e Eva desde uma perspectiva comparatista, isso é, remeterá o romance El infinito en la palma de la mano (2013), de Gioconda Belli não somente à sua individualidade, mas também ao jogo dialético/intertextual com a narração bíblica e alguns textos apócrifos versões do Velho e Novo Testamentos que não foram incorporados ao cânone eclesiástico mas que Gioconda descobre de maneira acidental - com a finalidade de mostrar que não há nada mais original e intrínseco a um texto que alimentar-se de outros textos e que nesse ritual latino-americano de transgressão ao modelo está subjacente o descobrimento e a conquista do paraíso latino-americano.

PALAVRAS-CHAVE: Literatura Comparada; El infinito en la palma de la mano (2003); Intertextualidade; "Entre-lugar”; Literatura hispano-americana.

RESUMEN: La idea de la escritura de ese texto surgió como respuesta a algunas inquietudes suscitadas a lo largo de los estudios sobre Literatura Comparada en América Latina y las posiciones defendidas por teóricos como Coutinho (19952004), Santiago (2000), Bernd (1998), entre otros. Entre ellas está la necesidad imperiosa de tomar conciencia de las especificidades de las diversas literaturas y de establecer un diálogo en pie de igualdad entre las mismas. Esto es, abordar específicamente la literatura de los distintos países latinoamericanos como una dialéctica entre lo local y lo universal porque es en esa pluralidad donde ella puede y debe ser entendida ya que las literaturas latinoamericanas siempre han recibido una gran influencia de las europeas y asimilaron de éstas, como de otras, aspectos y características que, sin embargo, en el presente son sustancialmente modificadas en el momento de la apropiación. Por eso este artículo analizará la reconstrucción de la historia de Adán y Eva desde una perspectiva comparatista, es decir, remitirá la novela El infinito en la palma de la mano (2013), de Gioconda Belli no sólo a su individualidad sino también al juego dialéctico/intertextual con la narración bíblica y unos textos apócrifos - versiones del Viejo y Nuevo Testamento que no fueron incorporados al canon eclesiástico pero que Gioconda descubre de manera accidental - con la finalidad de mostrar que no hay nada más original ni intrínseco a un texto que alimentarse de otros textos y que en ese ritual latinoamericano de transgresión al modelo yace el descubrimiento y la conquista del paraíso latinoamericano.

PALABRAS CLAVE: Literatura Comparada; El infinito en la palma de la mano (2013); Intertextualidad; "Entre-lugar"; Literatura hispanoamericana.

\section{INTRODUCCIÓN}

Gioconda Belli nació en Managua, ciudad capital de Nicaragua, en 1948. Ella comienza su educación primaria en el Colegio de la Asunción y a la edad de catorce años ingresa como interna al Real Colegio de Santa Isabel en España. Terminado su bachillerato, estudió inglés, publicidad y periodismo en Filadelfia y, al concluirlos, regresó a su país natal donde obtuvo su primer trabajo como ejecutiva en una agencia de publicidad. Poco tiempo después, Belli conoció a su primer marido, Mariano Argüello, y dio a luz a su primera hija, Maryam.

Volume 18

Número 40 


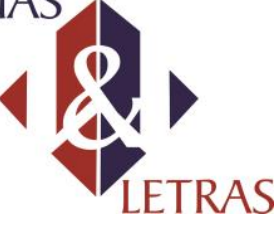

e-ISSN: 1981-4755

DOI: $10.5935 / 1981-4755.20170014$

En uno de sus trabajos conoció a algunos escritores y artistas, miembros del Frente Sandinista de Liberación Nacional (FSLN), y animada por ellos no sólo empezó a escribir sus primeros poemas sino también se unió al movimiento en 1970. En medio de esta actividad política y literaria, cuatro años más tarde, nace su segunda hija, Melissa, y en 1975 se vio obligada a exiliarse, primero en México y luego en Costa Rica, dejando al cuidado de su esposo a sus dos niñas.

Desde el exilio, Gioconda siguió colaborando con el FSLN no sólo recaudando fondos para el movimiento sino denunciando en Europa y en Sudamérica las violaciones de los derechos humanos de los nicaragüenses bajo el régimen somocista. A finales de 1976, la escritora y activista política conoció al periodista brasileño Sergio de Castro, quien sería su segundo marido y padre de su hijo Camilo, pero la relación no duró mucho debido a la muerte de éste. Tras el triunfo de la Revolución sandinista, el 19 de julio de 1979, Gioconda regresó a Nicaragua y continuó su carrera profesional sirviendo al gobierno, al mismo tiempo se involucró con el renacimiento cultural de su país y con la lucha por los derechos de la mujer. Finalmente, en 1987, Belli se casó con Charles Castaldi, un periodista americano, con quien vive actualmente en Santa Mónica y con quien tuvo a su hija Adriana, y, además, se dedicó a escribir; por eso, hoy, Gioconda Belli es una reconocida y premiada poeta, novelista y ensayista.

Esta semblanza biográfica de Gioconda Belli ayuda a mostrar y a definir su tarea como autora latinoamericana. El camino de los escritores de la tierra conquistada por los europeos en 1492 implica un recorrido contrario al impuesto por los colonizadores españoles y al fijado por los posteriores colonos surgidos de la sociedad mestiza. Por eso, escribir en ese contexto socio-histórico y cultural latinoamericano es escribir en contra de cualquier dominación y el texto resultante de ese ejercicio de lectura y escritura - acciones libertarias por muchos años controladas por los detentores del poder - es un manifiesto de oposición a los valores culturales impuestos por los viejos o nuevos conquistadores.

En las sociedades estructuradas en nuestro continente, al final del siglo XV había el predominio del lenguaje oral. Así, el proceso de colonización de América es marcado por el enfrentamiento entre la oralidad cultivada por toda la población nativa ya existente en esas tierras y la escritura traída e impuesta por los europeos que acababan de dominarla. El alcance de la disparidad entre estas dos modalidades de lenguaje como formas de ejercer el poder - es visto como uno de los factores, entre otros, que posibilitó el dominio de los europeos sobre las naciones autóctonas.

Volume 18

Número 40 


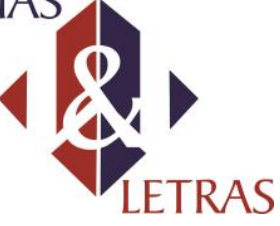

e-ISSN: 1981-4755

DOI: $10.5935 / 1981-4755.20170014$

Con la cultura de la escritura venida de Europa - la cual por varios siglos se encargó de escribir nuestro pasado siguiendo sus propias perspectivas - los habitantes nativos son sometidos a un sistema de comunicación que les es ajeno y desconocido, pero que, de ahora en adelante, regiría su existencia. La sustitución de los rituales de la memoria por los de la escritura logró, a lo largo de los 5 siglos y poco de dominación directa, borrar de nuestras tradiciones hasta el sagrado proceso del cultivo de la memoria individual y colectiva.

Según Foucambert (1994, p. 77), la escritura es el instrumento del pensamiento reflexivo y sólo el contacto con ella puede favorecer el desarrollo de un pensamiento abstracto, complejo y de naturaleza diferenciada de aquél permitido por el lenguaje oral. Es la escritura que permite la construcción de puntos de vista y de una visión de mundo, y también la atribución de sentido al mismo mundo. La lectura es aquella que va a la búsqueda de esos puntos de vista, verificándolos, cuestionándolos e investigando los medios de su elaboración. Apoderarse de esos conocimientos y ejercitarlos son, para los latinoamericanos, vías para la descolonización, de liberación y de consolidación de una identidad híbrida y mestiza que rechaza la imposición de los preceptos de unidad y pureza introducidos por los europeos. De acuerdo con Santiago (2000, p. 18) " "estos dos conceptos pierden el trazado exacto de su significado, pierden el peso aplastador, su señal de superioridad cultural, a medida que el trabajo de contaminación de los latinoamericanos al canon europeo se afirma, se muestra más y más eficaz." La escritura de Gioconda Belli es una muestra preciosa de ese proceso.

Así lo demuestra Gioconda, por ejemplo, en su segundo libro de poemas titulado Línea de fuego, poemario que fue dedicado a sus compañeros del FSLN y que la convirtieron, por su temática política y su conciencia de la mujer sexual y guerrera, en el símbolo femenino de la revolución sandinista, además de obtener con ésta producción el premio Casa de las Américas. Eso pasa también en su quinta novela denominada $E l$ infinito en la palma de la mano (2013), donde - en virtud del hecho de que América Latina no puede negar ni cerrar sus puertas a la dominación extranjera o interna, real o la que subyuga al entendimiento - instituye el desvío y la destrucción del código religioso impuesto para redescubrir y conquistar el paraíso perdido. Las estrategias y los recursos escriturales empleados para lograrlo en su novela es lo que veremos a seguir.

\footnotetext{
${ }^{4}$ Las citas de los teóricos brasileños se hacen en Lengua Española por nuestra traducción. Volume 18 


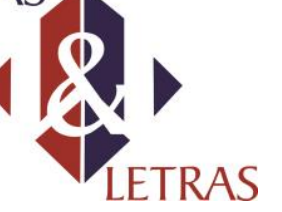

e-ISSN: 1981-4755

DOI: $10.5935 / 1981-4755.20170014$

GÉNESIS, GRANDES LIBROS SECRETOS Y EL INFINITO EN LA PALMA DE LA MANO (2013)

En una nota que precede a la novela, Gioconda Belli refiere que su novela $E l$ infinito en la palma de la mano "se originó en el asombro de descubrir lo desconocido en una historia que, por antigua, creía conocer de toda la vida" (BELLI, 2013, p. 11). Luego, también expresa que "la idea de reconstruir el drama de Adán y Eva en el Paraíso Terrenal fue el resultado de un hecho fortuito" (BELLI, 2013, p. 11) ya que, forzada a esperar un rato largo en la biblioteca de un familiar, encontró entre los anaqueles un tomo titulado Grandes libros secretos. Según la introducción de dicho ejemplar, se trataba de una recopilación de libros rechazados por quienes editaron los textos sagrados y entre los cuales se hallaban los Libros de Adán y Eva. Fascinada por el descubrimiento, Gioconda no sólo leyó en ese momento el texto apócrifo sino que investigó y encontró una serie de manuscritos e historias bíblicas perdidas como los Pergaminos de la biblioteca de Nag Hammadi, los Pergaminos del mar Muerto y los Midrás, comentarios escritos por doctos rabinos a lo largo de muchos siglos. Así vemos cómo Gioconda Belli es primero lectora y luego escritora ya que el conocimiento alimenta y estimula su proyecto creador, porque, como dice Silviano Santiago (2000, p. 20), para los escritores latinoamericanos “[...] las palabras del otro tienen la particularidad de presentarse como objetos que fascinan sus ojos, sus dedos, y la escritura del segundo texto es, en parte, la historia de una experiencia sensual con el signo extranjero". La historia de la escritura de esa novela confirma otro de los apuntamientos hechos por Santiago (200, p. 25): “el escritor latinoamericano es el devorador de libros de que los cuentos de Borges nos hablan con insistencia. Lee todo el tiempo y publica de vez en cuando".

El infinito en la palma de la mano (2013) es una ficción que surge por la meditación traicionera sobre los textos leídos, y Gioconda lectora, transformada en autora, sorprende los textos fuentes en sus limitaciones para evocar y crear su visión del tema presentado por los originales. Así es como los textos legibles de los que nos habla Barthes (1992) - y a los que se refiere Santiago (2000) - invitan al lector a aventurarse a la práctica de los textos escribibles, es decir, así es como el Génesis y los Grandes libros secretos animaron a la invención de El infinito en la palma de la mano (2013), donde Belli revisa el mito de Adán y Eva y la pérdida del Paraíso para ofrecer una nueva versión de la creación a partir de su visión latinoamericana.

Volume 18

Número 40 


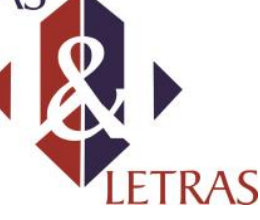

e-ISSN: 1981-4755

DOI: $10.5935 / 1981-4755.20170014$

El Génesis es la historia de una familia, la de Abraham, y como preparación providencial a esta historia familiar, nos da, en los once primeros capítulos, la historia del mundo y del hombre, la historia de la civilización y de la cultura, trazando de este modo a través de las edades la línea del plan salvífico de Dios en la preparación y elección de Israel como pueblo escogido.

Este libro bíblico se divide en dos partes de extensión desigual. Por un lado, relata la historia primitiva desde la creación hasta Abraham, distribuida de este modo: la creación y la caída, la historia de la cultura, el diluvio y del diluvio hasta Abraham. Y, por el otro, cuenta la historia de los Patriarcas con la siguiente distribución: Abraham, Isaac y Jacob, y José.

Además, junto a esta división, el mismo libro nos proporciona otra que concebida por la fuente Sacerdotal - distribuye la obra en diez secciones: origen del cielo y de la tierra, historia de Adán, historia de Noé, historia de los hijos de Noé, historia de Sem, historia de Teraj, historia de Ismael, historia de Isaac, historia de Esaú e historia de Jacob.

De la misma manera, El infinito en la palma de la mano (2013) es la historia de una familia, la de la humanidad; y la novela - con excepción de la última división también está estructurada en dos partes: la primera, "Hombre y mujer los creó", narra la creación de Adán y Eva, la desobediencia, el destierro del Paraíso y la lucha del primer hombre y la primera mujer por sobrevivir en un mundo hostil y desconocido. La segunda parte, "Creced y multiplicaos", es el relato de la descendencia de la pareja original, y es tan fascinante como la primera. Incluye en su trama un crimen, con ingredientes tan universales como la pasión, los celos, la injusticia de Dios, la imposibilidad del perdón, el castigo divino, el destierro y la lucha por la supervivencia.

Sin embargo, algunas de las diferencias con el texto legible (Génesis) son que en el texto escribible (El infinito en la palma de la mano) por un lado, la escritora nicaragüense rescribe la figura de Eva para reivindicar a la mujer humilde y desligarla de esta manera del papel de pecadora y causante de la caída del hombre que la versión cristiana le ha asignado. Por otro lado la novela de Belli desmitifica la creación de la humanidad y la reconstruye dándole un enfoque evolucionista, como se puede ver en el análisis a seguir. 


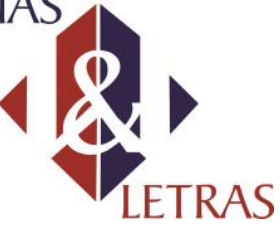

Analizar el drama de Adán y Eva en la novela El infinito en la palma de la mano (2013) implica establecer un diálogo con el Génesis para mostrar cómo la autora latinoamericana se apropia, contamina, destruye, metamorfosea, transfigura y crea su propia versión acerca de los orígenes de la humanidad. Tal proyecto escritural se ubica, como bien señaló Silviano Santiago (2000), en el "entre-lugar" del discurso latinoamericano. La parodia a la que le lanza Gioconda está, pues

[...] entre el sacrificio y el juego, entre la prisión y la transgresión, entre la sumisión al código y a la agresión, entre la obediencia y la rebelión, entre la asimilación y la expresión - allí, en ese lugar aparentemente vacío, su templo y su lugar de clandestinidad, allí, se realiza el ritual antropófago de la literatura latinoamericana. (SANTIAGO, 2000, p. 26).

Además, en ese proceso de comparación, podremos observar cómo el texto de Belli se convierte en responsable por la revitalización de la historia, en definitiva, de cada uno de nosotros. Así, al proceder la relectura y reescritura de la historia de la creación del hombre y de la mujer segundo los preceptos religiosos traídos por los europeos a las tierras que llamaron de americanas, la escritora nicaragüense transciende a la tradición del canon y

[...] el texto segundo, en el proceso de la comparación, no es solamente el 'deudor', sino también el responsable por la revitalización del primero; y la relación entre ambos, en vez de unidireccional, adquiere sentido de reciprocidad convirtiéndose, en consecuencia, en más rica y dinámica. Lo que prevalece en la lectura comparatista ya no es la relación de semejanza o continuidad, siempre desventajosa para el texto segundo, sino el elemento de diferenciación que este último introduce en el diálogo intertextual que establece con el primero. (COUTINHO, 1995, p. 625-626)

La historia de la humanidad - descendente del primer hombre, Adán, y de la primera mujer, Eva, de acuerdo con la creencia judaico-cristiana occidental - recibe nueva perspectiva en la imaginación novelesca de Belli que, entre otros elementos de diferenciación, introduce en su relato un distinto papel, más activo, práctico y decisivo, para la mujer. Esa nueva configuración del personaje Eva en El infinito en la palma de la mano (2013), obliga al lector a una nueva confrontación frente a los pilares básicos de la cultura occidental. 


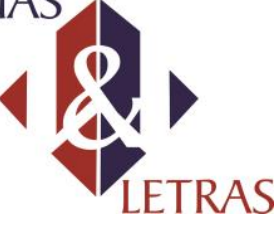

e-ISSN: 1981-4755

DOI: $10.5935 / 1981-4755.20170014$

El Génesis, como se puede leer en la introducción de la Biblia Sagrada (1970, p. $10-14)^{5}$ es el primer libro de los cinco que conforman el Pentateuco en el Antiguo Testamento y narra los orígenes del mundo y del género humano hasta los comienzos de la formación del pueblo de Israel en Egipto. Según los apuntes hechos en la edición de la Biblia Sagrada que usamos, desde el punto de vista literario, no es una obra de un solo autor sino que está compuesta por redacciones sucesivas que han ido incorporando tres fuentes o tradiciones: la Yavista, la Elohísta y la Sacerdotal.

La historia cristiana de la creación y la pérdida del paraíso que se presenta en los primeros capítulos del Génesis está compuesta por la combinación de las fuentes Yavistas y Sacerdotales. De las dos versiones de la creación, la Yavista es la que ha influido aparentemente en la producción de Gioconda Belli, pero antes de mostrar cómo se lleva a cabo esto en la novela, cabe destacar que el documento Yavista, el cual comienza en el capítulo 2, versículo 4 b y se extiende hasta el final del capítulo 3, se remonta al siglo IX o $\mathrm{X}$ a.C. aunque yace una tradición oral aún más antigua detrás de él. Este segundo relato comienza con la formación del primer hombre y con la plantación de un jardín en el Edén donde Yavé Dios lo pondrá antes de que le saque una costilla para llevar a cabo la creación de la mujer:

Entonces Yavé Dios formó al hombre del polvo de la tierra, le insufló en sus narices un hálito de vida y así llegó a ser el hombre un ser viviente. [...] Plantó después Yavé Dios un jardín en Edén, al oriente, y en él puso al hombre que había formado. [...]. Tomó, pues, Yavé Dios al hombre y le puso en el jardín de Edén para que lo cultivase y guardase. (GÉNESIS: cap. 2 -v. 7, 8, 15 - BIBLIA SAGRADA, 1970, p. 17)

El infinito en la palma de la mano (2013), en cambio, se inicia con el relato de cómo Adán es creado y cómo despierta a la vida. Desde el comienzo, Gioconda Belli homologa la vida a la conciencia, así lo expresa el narrador cuando dice: "Y fue. Súbitamente. De no ser, a ser consciente de que era. Abrió los ojos, se tocó y supo que era un hombre, sin saber cómo lo sabía. Vio el Jardín y se sintió visto" (BELLI, 2013, p. 17). Es esta conciencia - entendida no sólo como propiedad del espíritu humano de reconocerse en sus atributos esenciales y en los cambios que experimenta en sí mismo sino como conocimiento interior del bien y del mal - la que Adán y Eva guardarán y resignificarán una vez expulsados del paraíso.

\footnotetext{
${ }^{5}$ Utilizamos la traducción de la Biblia hecha en equipo bajo la dirección del Dr. Evaristo Martín Nieto, de la editorial Ediciones Paulinas.

Volume 18

Número 40
} 


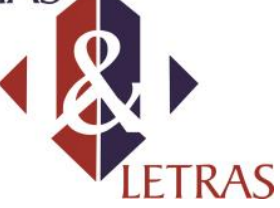

e-ISSN: 1981-4755

DOI: $10.5935 / 1981-4755.20170014$

Será esa autoconciencia la que les permitirá al primer hombre y a la primara mujer reflexionar, sin falsedad ni invención, sobre la insólita existencia, porque es justamente la conciencia la que coloca al hombre ante la realidad, la que lo integra como parte del mundo y no solamente como un sujeto en el mundo. El poder de la conciencia es la que puede de hecho libertar y hacer con que el nuevo ser venga a asumirse en su plenitud. Esa es, pues, una nueva diferencia que la escritura de Belli propone a los lectores frente a los antiguos dogmas de la religión; una visión de la historia de la humanidad que relativiza los designios de Dios con la consciencia humana.

En la novela, aparentemente la creación de Eva se manifiesta como es relatada en el documento Yavista: "Yavé Dios hizo caer sobre el hombre un sueño letárgico, y mientras dormía tomó una de sus costillas, reponiendo carne en su lugar; seguidamente de la costilla tomada al hombre formó Yavé Dios a la mujer y se la presentó al hombre" (GÉNESIS: cap. 2 -v. 21-22 - BIBLIA SAGRADA, 1970, p. 18); pero, en realidad, la autora centroamericana juega con la pieza de la costilla ya que nunca se declara que Eva haya sido creada de la costilla de Adán.

Lo que la voz narrativa nos dice es que el primer hombre "más tarde recordaría el cuerpo abriéndosele, el tajo dividiéndole el ser y extrayendo la criatura íntima que hasta entonces habitaba en su interior" (BELLI, 2013, p. 19), una imagen antropomórfica que servirá para explicar el despertar del deseo y el encuentro de los cuerpos una vez que coman el fruto prohibido. Y, será, justamente, ese retorno a ser un solo cuerpo satisfecho lo que les permitirá recrear el principio del mundo y de la historia porque sabrán que nunca más existirá la soledad para ellos.

De este modo, Belli desmitifica la manera en que la primera mujer fue creada y consiguientemente propone la igualdad de los géneros ya que su interpretación termina coincidiendo con la primera versión de la creación, la del documento Sacerdotal: "Dios creó al hombre a su imagen, a imagen de Dios lo creó, macho y hembra los creó" (GÉNESIS: cap. 1 -v. 27 - BIBLIA SAGRADA, 1970, p. 16), por lo tanto, según esta historia, el hombre y la mujer fueron creados al mismo tiempo y a imagen y semejanza de Dios.

Otro aspecto que la escritora latinoamericana desmitifica en El infinito en la palma de la mano es la culpabilidad que se le ha imputado a Eva sobre la pérdida del paraíso. El autor bíblico expone las razones cuando Dios le dijo al hombre: "Porque has seguido la voz de tu mujer y porque has comido del árbol del que te había prohibido comer, maldita sea la tierra por tu culpa" (GÉNESIS: cap. 3 -v. 17 - BIBLIA Volume 18

Número 40 


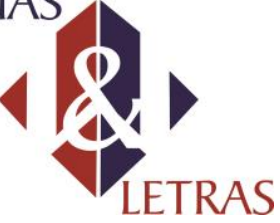

e-ISSN: 1981-4755

DOI: $10.5935 / 1981-4755.20170014$

SAGRADA, 1970, p. 20) y les impone a cada uno penas correlativas a su misión y naturaleza, es decir: Adán con el sudor de su frente sacará alimentos de la tierra todo el tiempo de su vida y Eva parirá sus hijos con dolor y, además, su deseo la arrastrará hacia su marido, que la dominará.

En cambio, en la novela, Belli nos muestra que si bien la primera mujer comió del Árbol del Conocimiento fue porque así estaba dispuesto por Dios, aquí llamado Elokim, y la Serpiente es quien se lo revela cuando expresa:

Adán y tú, a diferencia de todas las criaturas del Universo, poseen la libertad de decidir lo que quieren. Son libres de comer o no comer de este árbol. Elokim sabe que la Historia sólo comenzará cuando usen esa libertad, pero ya ves, tiene miedo de que la usen, teme que su creación termine pareciéndosele demasiado. Preferiría contemplar eternamente el reflejo de su inocencia. Por eso les prohíbe que coman del árbol y decidan ser libres. (BELLI, 2013, p. 28)

Así, la Serpiente no sólo introduce el tema del libre albedrío sino que, a través de su comentario, le presenta un Dios (Elokim) que actúa de manera impulsiva y que, además, se muestra temeroso de su propia creación. Luego de este mensaje, Eva dedicará mucho tiempo a reflexionar sobre el deseo de comer la fruta prohibida y se convencerá de que si Elokim no hubiese querido que comieran la fruta no les habría inspirado el deseo de hacerlo ni habría guiado sus pasos hacia el Árbol. Por eso, ante el temor, el arrepentimiento y los reproches de Adán por la expulsión del Paraíso, Eva responde: "Te lo dije. Él quería que yo comiera la fruta. Eso me hizo sentir. Quiere saber qué resultará de nosotros. Para eso nos hizo libres" (BELLI, 2013, p. 60).

Por eso, el personaje femenino es creado con un temperamento curioso y reflexivo, pues, de acuerdo con la descripción del narrador, "la docilidad no estaba en su naturaleza. Lo mejor de ella era su incapacidad de estarse quieta, la vivacidad con que miró e interrogó todo desde el principio" (BELLI, 2013, p. 33). Es decir, en esta obra ficcional, la escritora plantea que Dios creó a Adán y a Eva para que éstos comenzaran la Historia de la humanidad. Empero, Dios escoge a Eva para que lleve a cabo el auténtico principio de los seres humanos y se lo revela a través de una visión mientras ella caminaba por el borde del río:

Un burbujeo ascendió súbito del fondo y un ojo salido de quién sabe dónde abrió sus párpados, la miró y al hacerlo le concedió ver a través de su tembloroso cristalino imágenes fascinantes y vertiginosas en las que ella mordía el higo y de ese minúsculo incidente brotaba una espiral gigantesca de hombres y mujeres efímeros y transparentes que

Volume 18

Número 40 


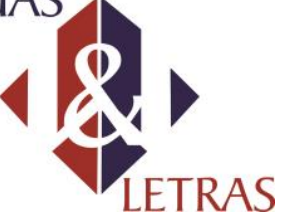

se multiplicaban, se esparcían por paisajes magníficos, sus rostros iluminados con gestos y expresiones incontables, sus pieles reflejando desde el brillo de los troncos húmedos hasta el pétalo pálido de los rododendros. Alrededor de ellos surgían formas, objetos sin nombre entre los que se movían con aplomo y sin prisa, inquisitivos y curiosos, persiguiendo una multiplicidad de visiones que se ramificaban a su vez mostrando honduras, estratos de símbolos incomprensibles sobre cuyo significado argüían enfrascados en ruidos y armonías confusas, pero cuyo eco resonaba en el interior de ella como si, al desconocerlos, los conociera. (BELLI, 2013, p. 34-35)

Mediante estas imágenes, Elokim, quien nunca aparece de forma directa en el relato a diferencia del Dios bíblico, le muestra a Eva una realidad más contundente que la del mismo jardín, a su vez que le comparte la abundancia de vida que lo inunda y con cuya profusión desbordante e irreprimible llevará a cabo el destino de seres que, movidos por la libertad de elección, comerán el fruto prohibido para hacer existir ese mundo. Elokim es un Dios que incita a desobedecer su mandato porque siente curiosidad de ver a esos seres creándose a sí mismos y destruyéndose entre sí, así lo demuestra en las últimas imágenes que comparte con Eva y que ésta percibe en el agua:

En el acelerado rodar de ciclos sucesivos, los vio ocultos y confundidos arder y contorsionarse, crear y dominar terribles conflagraciones de las que emergían, una y otra vez. [...] Curiosamente, la última imagen que surgió cuando el agua aún no terminaba de aquietarse fue tan plácida y clara que no logró saber si era ella la que volvía a saberse en el Jardín o si el misterio del final de todo aquello era la posibilidad de regresar al principio. (BELLI, 2013, p. 34-35)

Después de esta visión, Eva entiende el plan divino: "La Historia, se dijo. La había visto. Era eso lo que empezaría si ella comía la fruta. Elokim quería que ella decidiese si existiría o no todo aquello. Él no quería hacerse responsable. Quería que fuese ella quien asumiera la responsabilidad” (BELLI, 2013, p. 35). Así, Eva cruzó la pradera y, cuando llegó al centro del jardín, al pie del árbol prohibido "no estaba siquiera segura de tener el valor de hacer lo que su conciencia le dictaba, pero no tenía alternativa" (BELLI, 2013, p. 42) porque era de la única manera en que

[...] harían la Historia para la que habían sido creados: fundarían una especie, poblarían un planeta, explorarían los límites de la conciencia y el entendimiento. Sólo ella, usando su libertad, podría darle a Elokim la experiencia del Bien y del Mal que Él anhelaba. Los había hecho a su imagen y semejanza para que tomaran la creación en sus manos (BELLI, 2013, p. 39) 


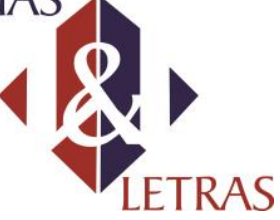

e-ISSN: 1981-4755

DOI: $10.5935 / 1981-4755.20170014$

Por lo tanto, en esta rebelión, transgresión y expresión del mito del paraíso perdido, Gioconda Belli nos propone una historia nueva de los comienzos de la humanidad en la cual Eva deja de ser culpable para constituirse en co-creadora, y la manera en que se convierte en madre de la especie humana es cuando Aklia, su segunda hija mujer, retoma al final de la novela algunas características que tenía al nacer y desarrolla otras asumiendo así su destino de mono. De cierta manera, la Serpiente que a lo largo del relato aparece para responder algunas dudas a Eva le va dando indicios también de lo que sucederá cuando le dice, por ejemplo:

[...] cuando los sacó del Jardín, Elokim trastornó la dirección del tiempo. En el Jardín eras eterna. Jamás habrías tenido hijos. No era necesario que te reprodujeras puesto que nunca morirías. Ahora la realidad debe ser recreada. La creación debe volver al punto donde pueda empezar de nuevo (BELLI, 2013, p. 162)

También, cuando al nacer el primer par de gemelos, expresa: “Tus hijos, Eva, tus hijos retornarán el tiempo a su inicio. Debes alimentarlos” (BELLI, 2013, p. 162). Así, en el segundo parto nacen Abel y Aklia, y de ésta su padre comenta "que parecía una mona, no un ser humano" (BELLI, 2013, p. 179) porque era "una criatura diminuta, los ojos apretadamente cerrados, la cara cubierta de vello oscuro, la frente abombada, los labios demasiado grandes" (BELLI, 2013, p. 179).

Finalmente, cabe destacar el momento en que la Serpiente le informa a Eva que Aklia ha vuelto a la inocencia, "[...] una inocencia anterior al Paraíso, precursora del Paraíso. La Historia ha saltado de ti a ella ahora y un tiempo largo y lento está por empezar" (BELLI, 2013, p. 234). Por lo tanto, “[...] el final de los descendientes de Aklia será llegar al principio" (BELLI, 2013, p. 234). Después de que la Serpiente se diluyera para siempre, Eva vio llegar una manada de monos y, antes de dejar marchar a Aklia, le dijo "recuerda cuanto has vivido. Algún día hablarás de nuevo. Ahora vete. ¡Corre, hija, ve y recupera el Paraíso!’(BELLI, 2013, p. 236). Así es como, con este final, Gioconda Belli se convierte en una antropófaga de las interpretaciones religiosa y científica sobre los comienzos de la humanidad y propone su propia versión de los hechos.

Desde su perspectiva latinoamericana la escritora, en su ficción, reclama la circularidad temporal de los orígenes frente a la linealidad del tiempo histórico que pasó a imperar en ese espacio desde la llegada de la occidentalización europea y que fue una de las características impuestas por mucho tiempo por el canon literario dominante. Al 


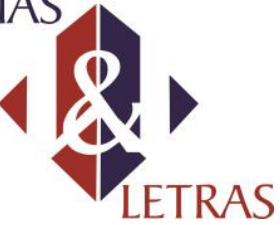

e-ISSN: 1981-4755

DOI: $10.5935 / 1981-4755.20170014$

referirse al pasado en el cual las literaturas latinoamericanas estuvieron bajo las imposiciones de las metrópolis Jean Bessière (2011, p. 23), menciona:

[...] más allá de ese confinamiento a un modo de repetición del modelo europeo, y en la inevitable constatación de la resistencia, estas literaturas son las literaturas de una historia diferente. [...] La situación de esas literaturas [...] debe considerarse ejemplar, y permite precisar la relación de las literaturas con la globalización. La globalización puede leerse, claramente, como un incremento de la interpenetración de las culturas y las expresiones literarias vinculadas a ellas, sean cuales sean las desigualdades que lleve en sí misma la globalización.

Así, el camino de los pueblos latinoamericanos en la práctica comparativista pasa, necesariamente, por los procesos de desterritorialización de los espacios imaginarios que les fueron tomados y ocupados a lo largo de los siglos para reterritorializarlos, impregnándolos con la sustancia de su propia sangre e imprimiéndoles su aliento híbrido y mestizo, rasgos de su propia originalidad, conforme defiende también el novelista paraguayo Augusto Roa Bastos (1992, p. 123) en su novela Vigilia del Almirante. Es esa la forma con la que se enfrenta el ser híbrido latinoamericano con su 'angustia de la influencia'.

Conforme comenta Coutinho (1995, p. 622), "los autores latinoamericanos de hoy saben, [...], que [su producción] no se limita a las fronteras de su país o su continente, y que su radio de actuación alcanza a veces vastas dimensiones. En obras como El infinito en la palma de la mano (2013) queda evidente que

[...] ahora, lo que se caracterizaba como copia imperfecta del modelo instituido por la cultura central pasa a ser visto como respuesta creativa; y el desvío de la norma se valora por la desacralización que efectúa sobre el objeto artístico. Los criterios hasta entonces incuestionables de originalidad y anterioridad son lanzados por tierra y el valor de la contribución latinoamericana pasa a residir exactamente en la manera como ella se apropia de las formas literarias europeas y las transforma, confiriéndoles nuevo vigor. (COUTINHO, 1995, p. 626)

Así, por la escritura paródica, intertextualizada, híbrida, mestiza los latinoamericanos emprenden su conquista del paraíso, por el proceso de reterritorialización de los espacios simbólicos que antes les fueron tomados por las ideologías colonialistas. Para Bernd (1998, p. 18), en la contemporaneidad "son los procedimientos de desterritorialización de procesos simbólicos los que engendran culturas híbridas, procesos de conversión y reciclaje de aportes de la modernidad que 


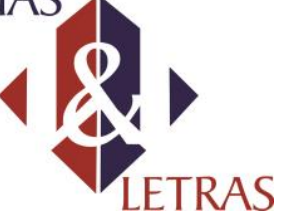

e-ISSN: 1981-4755

DOI: $10.5935 / 1981-4755.20170014$

son adaptados al medioambiente". Para la comparatista brasileña, frente a las producciones literarias latinoamericanas, el trabajo del comparatista debe considerar las especificidades con las cuales se enfrentará si su interés es el de emprender la interpretación de literaturas en situación periférica como se consideró por mucho tiempo a las del ámbito latinoamericano, "concibiéndose a los autores y a las obras en régimen de comunión de un hipertexto virtual y heterogéneo, cabría además apuntar los puntos de convergencia que resultaron del uso del hipertexto común [...]” (BERND, 1998, p. $18)$.

Segundo comenta ella, es el lector quien, en el proceso de lectura, "emprenderá el develamiento de esos puntos a partir de un contrato de lectura que tenga por base la existencia, en los autores y en las obras, de un sentimiento americanizado, necesariamente heterogéneo, y de una poética americana, necesariamente múltiple e imprevisible”. (1988, p. 26-27). Esas son, seguramente, lecturas que no sólo cautivan al lector, pero también le ponen frente a una nueva realidad que buscan evidenciar los artistas latinoamericanos para que, así, juntos - escritor y lector - puedan caminar por las vías de descolonización tan necesarias aun en nuestro continente.

\section{CONCLUSIÓN}

Los contextos de producción literaria en el ámbito latinoamericano, casi sin excepción, revelan su carácter híbrido: una mezcla entre las herencias e imposiciones provenientes de la metrópolis y la tentativa de los escritores por incursionar en lo auténtico de nuestra realidad. De acuerdo con lo que expone Coutinho (1995, p. 628), la producción literaria en América latina en la contemporaneidad vive un momento especial pues,

[...] se trata, antes, de un proceso complejo en que los aportes de la literatura europea se mezclan con las formas o tendencias acá existentes, y dan origen a manifestaciones nuevas, que contienen elementos tanto de la forma apropiada cuanto de la que ya existía anteriormente en el continente. Como se ve, hay pérdidas y ganancias parciales en ambos lados y el resultado trae en sí un sesgo de singularidad - su carácter amalgamado o híbrido - en franca homología con el mestizaje étnico y cultural que caracteriza el continente.

Insertar los estudios y las prácticas de literatura comparada, en el ámbito latinoamericano, con ese contexto de interrelaciones, deja de exponer solamente nuestra 


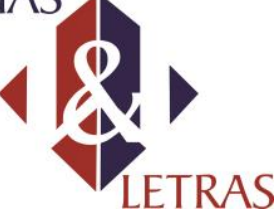

e-ISSN: 1981-4755

DOI: $10.5935 / 1981-4755.20170014$

dependencia para revelar también nuestras contribuciones. Como se puede ver en el texto analizado, si bien el conocimiento de los relatos bíblicos y la lectura de los apócrifos fueron el punto de partida para la escritura de El infinito en la palma de la mano (2013), la novela de Gioconda Belli es un texto que propone una dimensión distinta a la historia existencial y cultural. Así como los textos primeros contribuyeron a dar una explicación de la condición humana fuera del paraíso, el texto segundo nos abre los ojos a redescubrir y revivir las grandes preocupaciones existenciales de la humanidad desde los inicios de los tiempos con una estética tan propia como bella.

Así, Belli plasma en la primera parte de la novela un tono poético de sensualidad, descubrimiento y asombro por la creación, a pesar de los sucesos dramáticos de la transgresión a la prohibición y la posterior expulsión del Jardín; y manifiesta, en la segunda parte, una sensación de catástrofe acompañado de la impotencia de saber que todo está predestinado por el mandato de Elokim y así lo concebimos cuando sabemos por boca de la Serpiente que:

[...] el Mal, el Bien, todo lo que es y será en este planeta, se origina aquí mismo: en ti, en tus hijos, en las generaciones que vendrán. El conocimiento y la libertad son dones que tú, Eva, usaste por primera vez y que tus descendientes tendrán que aprender a utilizar por sí mismos. A menudo te culparán, pero sin esos dones la existencia se les haría intolerable (BELLI, 2013, p. 201)

La Serpiente con sabiduría renovada le recuerda a Eva que el único Paraíso donde la existencia es real es aquel donde los seres humanos posean la libertad y el conocimiento. De hecho, sabe también que Elokim desea que la especie humana encuentre la armonía para que le concedan el don del olvido y lo liberen de la soledad de su poder y así pueda marcharse a construir otros universos.

Por eso, lo que El infinito en la palma de la mano nos propone no es sólo una relectura bíblica y hermenéutica de la existencia humana sino un hombre y una mujer que son conciencia de sí y así conciencia del mundo, que son capaces de conocer y asumir riesgos, que son presencia creadora en cuanto eligen y deciden y se transforman a la vez que transforman un paraíso dado en un paraíso descubierto y conquistado, en definitiva, por una escritora latinoamericana para nuestra literatura.

De ese modo, por la propia práctica escritural y lectora actual, procedente del espacio conquistado, se evidencia lo que defiende Bernd (1998, p. 27) al mencionar que 


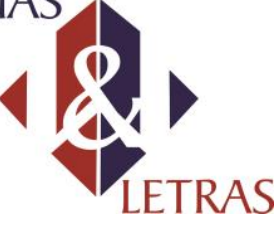

e-ISSN: 1981-4755

DOI: $10.5935 / 1981-4755.20170014$

[...] a una era de oposiciones binarias, de esencialismos y de culto a la pureza, que parece haber caracterizado a la modernidad, estaríamos pasando a otra marcada por heterogeneidades, polifonías y cruzamientos donde la recuperación identitaria estaría más atenta a la rescate de trazos, vestigios, fragmentos y de voces hasta entonces inaudibles, más allá del registro de las voces legitimadas y oficiales.

Son, por tanto, las vías de la escritura y de la lectura que abren las posibilidades a los ciudadanos del "Nuevo Mundo" para dar paso, pues, a tantas voces calladas, silenciadas y marginadas a lo largo de la historia escrita por el poder dominante para que puedan, en el contexto actual, manifestarse en toda su hibridez, mestizaje y plurisignificación. Es al realizarse el "ritual antropófago" de la literatura latinoamericano que sus artistas ejercen la libertad y la consciencia crítica. Esas, a su vez, se traducen en efectivos pasos a la descolonización.

\section{REFERENCIAS:}

BARTHES, R. S/Z. Trad. Léa Novaes. Rio de Janeiro: Nova Fronteira. 1992.

BELLI, G. El infinito en la palma de la mano. $1^{\circ}$ ed. Booket, Buenos Aires, 2013.

BERN, Z. (Org). Escrituras Híbridas: estudos em literatura comparada interamericana. Porto Alegre, Ed. UFRGS, 1998.

BESSIÈRE, J. Literatura Comparada e identificación de las diferencias literarias y culturales. In: CROLLA, A. (Org.). Lindes actuales de la literatura comparada. Santa Fe: Universidad Nacional del Litoral, 2011.

BIBLIA SAGRADA. Traducida de los textos originales en equipo bajo la dirección del Dr. Evaristo Martín Nieto, Ediciones Paulinas, Madrid, 1970.

COUTINHO, E. F. La literatura comparada en América Latina: sentido y función, p. 237-258. Voz y Escritura. Revista de Estudios Literarios. $\mathrm{N}^{\circ}$ 14, enero-diciembre 2004.

COUTINHO, E. F. Sem centro nem periferia: é possível um novo olhar no discurso teórico-crítico latino-americano? Congresso da ABRALIC Anais. Belo Horizonte: ABRALIC, 1995. Vol. 2, p. 621-633.

FOUCAMBERT, J. A leitura em questão. Porto Alegre: Artes Médicas, 1994.

ROA BASTOS, A. Vigilia del Almirante. Asunción: RP Ediciones, 1992.

SANTIAGO, S. O entre-lugar do discurso latino-americano, In: Uma literatura nos trópicos. 2. Ed. Río de Janeiro: Rocco, 2000, p. 09-26.

Data de recebimento: $11 / 11 / 2014$

Data de aprovação: 31/08/2017 